\title{
Cost-effective River Water Quality Management using Integrated Real-Time Control Technology
}

\author{
Fanlin Meng ${ }^{1}$, Guangtao $\mathrm{Fu}^{1 *}$, David Butler ${ }^{1 *}$ \\ ${ }^{1}$ Centre for Water Systems, College of Engineering, Mathematics and Physical \\ Sciences, University of Exeter, Exeter, EX4 4QF, UK
}

\section{Abstract}

Integrated real-time control (RTC) of urban wastewater systems is increasingly presented as a promising and emerging strategy to deliver improved surface water quality by responsive operation according to real-time data collected from the sewer system, treatment plant and the receiving water. However, the detailed benefits and costs associated with integrated RTC have yet to be comprehensively evaluated. Built on state-of-the-art modelling and analytical tools, a three-step framework is proposed to develop integrated RTC strategies which cost-effectively maximize environmental outcomes. Results from a case study show integrated RTC can improve river quality by over $20 \%$ to meet the "good status" requirements of the EU Water Framework Directive with a $15 \%$ reduced cost, due to responsive aeration with changing environmental assimilation capacity. The cost-effectiveness of integrated RTC strategies is further demonstrated against tightening environmental standards (to the strictest levels) and against two commonly used compliance strategies. Compared to current practices (seasonal/monthly based operation), integrated RTC strategies can reduce costs whilst improving resilience of the system to disturbances and reducing environmental risk.

\section{Keywords}


24 Environmental risk, integrated real-time control, operational cost, resilience analysis, urban wastewater systems

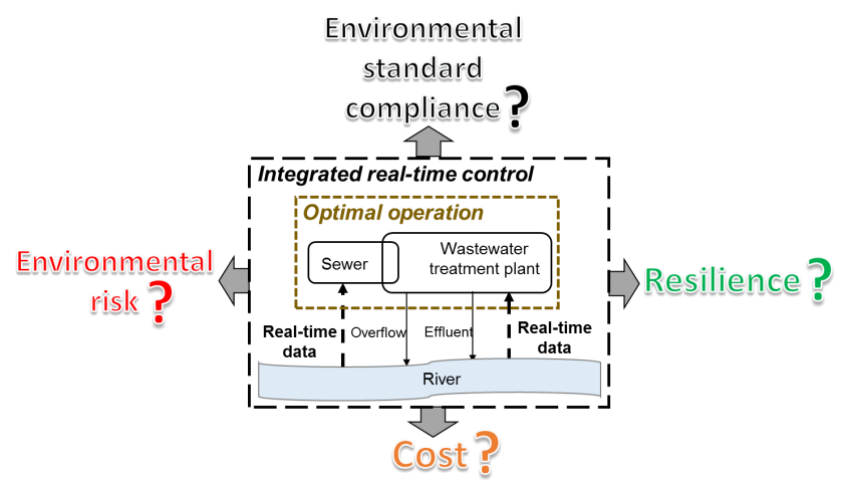

\section{Introduction}

Global water quality is under increasing pressure from population growth, urbanisation and climate change ${ }^{1,2}$. Urban wastewater treatment is a fundamental element in protecting the water environment, but requires large upfront capital investments (with repayment times of up to 20 years) ${ }^{3}$ and has significant operational costs (e.g. $3 \%$ of national electricity consumption in the USA $)^{4}$. With the focus shifting from end-of-pipe quality to direct environmental outcomes ${ }^{5}$, costs are expected to escalate to meet these greater expectations. For example, £27 billion from 2010 to 2030 is deemed as necessary in the UK to install additional treatment capacity to meet the "good status" requirements of the European Water Framework Directive (WFD) ${ }^{6}$.

To achieve environmental targets cost-effectively, non-conventional engineering solutions have been investigated and practiced in urban wastewater systems (UWWSs, consisting of the sewer system and wastewater treatment plant (WWTP)).

41 These include source pollution control such as green/grey infrastructure ${ }^{7,8}$, sewage 42 flow control to minimize overflows to sensitive sites $^{9,10}$, and optimal operation of WWTPs/UWWSs to maximize treatment efficiency against dynamic wastewater 
44 inflows ${ }^{11,12}$. Benefits gained by these measures result from enhanced understanding of wastewater processes, flexibility in system operation and/or spatial variability in the pollutant assimilation (dilution and/or degradation) capacity of the recipient. So far, the temporal variability in environmental capacity is largely neglected, though the recipient may be modelled to assess the expected environmental impacts of a solution over a certain period. This may lead to undesirable results whereby an UWWS runs as usual when the aquatic system becomes particularly sensitive to water quality stresses (e.g. under low flow conditions where concentrations of un-ionised ammonia increase to toxic levels) or the system runs in full power (e.g. aeration rate, pumping rate) when the environmental assimilation capacity is high ${ }^{13}$.

Indeed, time-based flexible operation of wastewater systems is allowed in some countries, though in simple forms, to exploit the dynamic self-purification capacity of the environment. For example, seasonal-based operation is permitted in the $\mathrm{UK}^{14}$ where winter flows are reported to be three times the summer ones in some typical rivers $^{15}$. This practice is also allowed in the USA and is further extended to monthlybased operation as differences in monthly flow rates are usually larger ${ }^{16}$. Investigations in Georgia, USA revealed capital and operational cost savings of up to $16 \%$ and $19 \%$ respectively by adopting monthly-based operation ${ }^{17}$. Yet existing practices cannot fully consider the stochastic, dynamic behaviour of rivers (high flows due to rainstorms can occur over periods of hours $)^{18}$, hence it is hard to keep an equilibrium between the environmental capacity and pollutant assimilation based on historical seasonal/monthly patterns. Moreover, the actual environmental consequences of the flexible operational practices have not been reported and need to be investigated. 

Integrated RTC is a promising approach to address the discrepancy between the pollutant assimilative need and environment capacity as it enables real-time (in hours to minutes) adjustment of UWWS operation with varying environmental conditions and/or wastewater inflows ${ }^{19-21}$. Built on integrated modelling of the UWWS and the recipient ${ }^{22}$, the benefits of integrated $\mathrm{RTC}$ have been demonstrated in the prior literature. For example, by controlling sewer overflow or inflow to the WWTP in accordance with real-time river quality, a $108 \%$ increase in minimum DO concentration $^{23}$ or a $12 \%$ decrease in peak ammonia concentration ${ }^{24}$ was demonstrated in the river. However, these simplistic indicators (the minimum or maximum) provide only a snapshot rather than a comprehensive view of environmental quality and offer limited perspectives on legislative compliance given other indicators (e.g. percentiles) are usually regulated. Evaluation periods (hours or days containing one or two storm events) have not been sufficiently long in prior literature to demonstrate the effectiveness of the strategy, as the biological response of activated sludge system is slow (e.g. requiring days to weeks to reach a steady state) and may have a non-linear relationship with rainfall intensity/duration ${ }^{17}$. Further, the cost-effectiveness of integrated RTC cannot be inferred from previous studies which were based on single control solutions and lacked cost analysis that is essential to understand the true value of the technology.

The aim of this paper is to present an integrated RTC framework for UWWSs to meet tightening environmental standards at lower cost using system control responsive to environmental changes. Building on state-of-the-art integrated UWWS modelling and analytics tools, optimal integrated RTC solutions are developed and assessed against tightening standards and comprehensive environmental quality indicators. A comparison analysis is made with current flexible operational practices to highlight the 
importance of environmentally responsive wastewater treatment informed by real-time information. This work uses the legislative framework of England and Wales as an example and is applied to a case study site with long-term input data sets.

\section{Methodology}

A three-step framework (Figure 1) is proposed for the development and appraisal of cost-effective integrated RTC solutions.

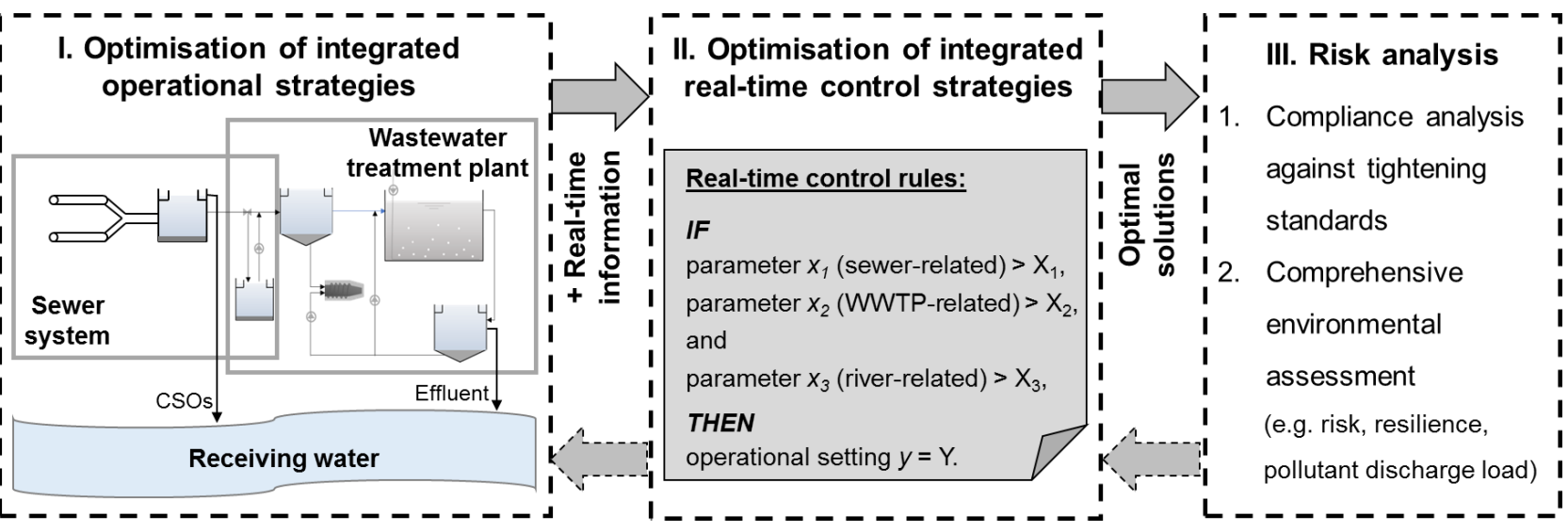

Figure 1 Framework for developing cost-effective integrated RTC strategies of urban wastewater systems

Step I: Based on integrated UWWS modelling, the operation of an UWWS is optimized to develop coordinated settings (e.g. pumping rate, valve opening position) with objectives of minimizing operational cost and minimizing/maximizing concentration of specific water quality parameter of concern (in regulatory statistical forms) in the recipient against the local context (i.e. wastewater input, precipitation and receiving water condition). This is performed as a prerequisite for control optimization as it is impractical and too costly to implement RTC at every operational handle; hence, the static settings of all operational handles are optimized first in this step before the introduction of control schemes at key operational handle(s) (see the selection of actuators in Step II). A range of computational methods of varying complexity could 
112 be linked to an integrated UWWS model for the optimization. For example, the Non-

113 Dominated Sorting Genetic Algorithm II (NSGA-II) ${ }^{25}$ is a popular evolutionary algorithm

114 for multi-objective optimization and has been demonstrated to be effective for urban

115 wastewater system management ${ }^{10,12,26,27}$. Other methods such as Latin Hypercube

116 Sampling (LHS) ${ }^{28}$ can also be used to find optimal operational solutions if the search

117 space is not deemed as large.

118 Step II: Integrated RTC solutions are developed to gain further benefits in the predefined cost and environmental objectives (i.e. concentrations of the investigated water quality parameter in different statistical forms) by effective use of real-time information. To achieve this, an integrated RTC procedure is established first to determine which real-time information is to be collected and utilized to guide the control of which operational settings for wastewater storage and/or treatment. Its development involves defining actuators (e.g. pumps, valves), sensors, control structures (linking actuators with measurement from sensors), and controller types (e.g. feedback control, feed-forward control, model-based predictive control) and algorithms (e.g. If-Then rules, decision matrix). Model-based predictive control is applied in this work as: a) it could utilize upstream monitoring to timely adjust system operation to achieve satisfactory environmental quality rather than compensating the deviation from the environmental goal after it has happened as in the case of feedback control, and b) it can be based on comprehensive system models without linearization (thus superior to feed-forward control) which is suitable for highly nonlinear UWWSs ${ }^{29}$. As such, sensors are placed at WWTP inlet and upstream of the receiving waterbody to gather information on influent pollutant loads and environmental assimilative capacity to guide the control action. Actuator(s) are chosen according to the suitability 
136 for frequent setting changes ${ }^{20,29}$ and their significance in influencing the control 137 objectives as identified by sensitivity analysis ${ }^{12,30}$.

138 After the establishment of the control procedure, the integrated RTC strategies are optimized against the same objectives defined in Step I but the decision variables are numeric parameters in the control algorithm, including control actions (e.g. pumping 141 rate, pumping time or air flow rate) and threshold values of system states for determining the control actions (e.g. river flow rate). Though capital investment may be incurred in setting up the control scheme such as purchasing controllers and (additional) sensors, it is not considered in the optimization as the capital cost does not vary among control solutions under the same RTC strategy framework. The optimisation can be performed online ${ }^{31,32}$ whereby optimisation is undertaken at each time step using real-time data to determine the best control actions to achieve predefined goals. Though it enables frequent update of the control strategies and/or system model, it is limited by the practical applicability such as its inability to consider long-term effects associated with water flow and quality changes ${ }^{33}$ and the simplification of system models to suit the intensive computational needs. As such, offline optimization ${ }^{33}$ is adopted in this study to enable a detailed and long-term appraisal of system performance. The control algorithm is pre-defined in the form of "If-Then" rules, which associate control actions in the consequent statement (i.e. 'Then') with criteria in the conditional statement (i.e. 'If'). The rules are optimised offline based on historical monitoring data and dynamic model simulation, however they are used online to trigger control actions based on real-time information from the sensors. 
Step III: Risk analysis is conducted to examine the performance of the optimal integrated RTC strategies against increasingly demanding regulatory requirements and various environmental impact indicators.

A spectrum of water quality standards is usually stipulated for different levels of environmental protection. In the UK, for example, water quality limits are formulated for five categories of water status ('high', 'good', 'moderate', 'poor' and 'bad') transposed from the WFD ${ }^{5}$. To deliver gradual improvement in surface water quality, environmental targets for local waterbodies are often raised steadily and incrementally between different status requirements along the spectrum. By simulating the tightening trend of the environmental standards, the potential of integrated RTC in accommodating future regulatory needs are identified.

Whilst environmental regulations are becoming more sophisticated, the extent of environmental impacts captured by regulatory parameters is still limited. For example, percentile (99\%ile or $90 \%$ ile $)^{34,35}$ and mean (averaged within an hour or 30 days) ${ }^{36}$ value limits on total ammonia concentration are imposed in England and Wales and the USA respectively to control the acute or chronic impacts of the pollutant. Yet these indicators cannot represent the occurrence, duration and accumulated impacts of (all) peak concentration episodes which are of great importance to the aquatic life. This limitation of the regulation indicators may partly explain the gap between achieving good environmental quality measured by water chemistry parameters and ecological criteria $^{37}$. As such, four surrogate indicators as below are employed to provide a broader picture of environmental consequences. They can be easily assessed by most environmental quality models without the need of applying comprehensive ecological models that require significant data inputs and model validation ${ }^{38}$. 
1) Environmental risk: The risk indicator proposed in Meng et al. $(2016)^{12}$ is calculated to estimate the accumulated impact of high pollutant concentration episodes. It is a product of the probability (measured as relative frequency) and consequences of water quality deterioration beyond the threshold limit.

$$
\text { Risk }=\sum\left(P_{C_{j}} \times \max \left(0, C_{j}-C_{\text {limit }}\right)\right)
$$

where $C_{j}$ is the concentration of the investigated pollutant in the recipient at time step $j$, which is regarded as a discrete random variable taking values at each time step; $C_{\text {limit }}(\mathrm{mg} / \mathrm{L})$ is the threshold limit; and $P_{C_{j}}$ is determined by dividing the duration of environmental quality being $C_{j}$ in a run by the total simulation time.

2) Resilience: A resilient system has many attributes, which include reduced failure number and duration when subject to unexpected or exceptional disturbances ${ }^{39}$.

- Failure number: A failure occurs when the environmental quality value falls below a predefined threshold (i.e. an environmental standard limit or any other value that suits local conditions). The total number of failures that occur in a simulation is counted.

- Failure duration: This refers to the total time of the ambient water quality being beyond the threshold limit during the assessed period (i.e. total duration of all failures).

3) Total discharge load: This lumped indicator records the contribution of an UWWS in discharging a pollutant to the environment. It is widely used in catchment management in placing a cap on the amount of pollutant emitted from a specific 
source. It is found to be effective in maintaining/improving environmental quality, especially in enclosed water areas with limited water exchange or rivers with dense wastewater discharge points ${ }^{40}$.

\section{Case Study}

\subsection{System Description}

The proposed framework is applied to an integrated UWWS ${ }^{8,12,22}$ which serves a population of about 150,000 producing an average dry weather flow (DWF) of 27,500 $\mathrm{m}^{3} / \mathrm{d}$. It consists of a sewer system ${ }^{41}$, a WWTP (Norwich, UK) ${ }^{42}$ and a hypothetical river $^{22}$. The layout of the integrated system is shown in Figure S1. The sewer system is laid across seven sub-catchments $\left(7.26 \mathrm{~km}^{2}\right.$ of impervious area) and has four online pass-through storage tanks at the downstream end of the catchments. The WWTP has a storm tank, a primary clarifier, an aeration tank, a secondary clarifier and a mechanical dewatering unit. The storm tank (off-line pass-through) starts to fill when the inflow rate to the primary clarifier reaches the maximum setting value and drains when it is below a threshold limit. The receiving river is $45 \mathrm{~km}$ in length (equally divided into 45 reaches) and has a base flow of $388,800 \mathrm{~m}^{3} / \mathrm{d}$ (dry weather dilution ratio is about 1:15). Details are provided as Supporting Information (Section S1) on the dimensions of the catchment and the treatment process units.

\subsection{Modelling of the Case Study}

223 The integrated modelling platform SIMBA $^{43}$ is employed to simulate the case study site. As provided in the model library, ASM1tm ${ }^{12,43}$ (an extension of Activated Sludge Model No. ${ }^{44}$ ) is used to simulate the nitrification processes in the WWTP. Lijklema ${ }^{45}$ (an extension of Streeter-Phelps model ${ }^{46}$ ) is used to model water quality processes in the river (e.g. reaeration, nitrification). The runoff and washoff in the catchment and 
sewers are represented by the $\mathrm{KOSIM}^{22}$ and $\mathrm{Nash}$ cascade approach ${ }^{47}$, and the hydrodynamic transport and transformation in the river by the Storm Water Management Model (SWMM5) ${ }^{48}$. All components of the integrated system can be run in a synchronous way by using the converter models. The integrated dynamic model enables detailed simulation of wastewater processes and the impacts of environmental (e.g. rainfall, temperature) changes on wastewater treatment efficiency.

To enable long-term simulations, a seasonal pattern is defined for the wastewater temperature and one-year 15-minute increment time series of rainfall and river (flow and water quality) data are applied based on historical records of a town in Southwest England. The quantity and quality of Dry Weather Flow (DWF) to the WWTP follow pre-defined diurnal patterns ${ }^{22}$, whilst the water quality of rainfall runoff and the supernatant flow from the sludge dewatering unit are assumed to be constant values $^{22,42}$. Details of the flow and/or water quality data of the rainfall, rainfall runoff, river flow, DWF and supernatant flow are presented in Section S1. Due to data availability and particular interest of the case study, total ammonia is investigated in this study to illustrate the framework. Nevertheless, the proposed framework should be readily applicable to other pollutants.

\subsection{Baseline Operational Scenario and Performance Assessment}

There are ten operational settings in the case study UWWS, which are the overflow thresholds of tanks 2, 4, 6 and 7 and the storm tank, emptying threshold and pumping rate of the storm tank (which is essentially a local control), aeration rate, return sludge pumping rate and waste sludge pumping rate. According to the simulation results with the one-year input data series, the $90 \%$ ile and $99 \%$ ile total ammonia concentrations 
252 between the standard limits for 'good status' (90\%ile: $0.3 \mathrm{NH}_{3}-\mathrm{N} \mathrm{mg} / \mathrm{L}, 99 \%$ ile: 0.7

$253 \mathrm{NH}_{3}-\mathrm{N} \mathrm{mg} / \mathrm{L}$ ) and 'moderate status' (90\%ile: $0.75 \mathrm{NH}_{3}-\mathrm{N} \mathrm{mg} / \mathrm{L}, 99 \%$ ile: $1.8 \mathrm{NH}_{3}-\mathrm{N}$

$254 \mathrm{mg} / \mathrm{L})^{34,35}$. Hence, optimization is undertaken in Steps I and II to develop optimal 255 operational/control solutions that minimize cost and pollutant concentration values as 256 defined in Equations (2) to (4), subject to constraints of meeting good status 257 requirements. More stringent standards up to 'high status' requirements (90\%ile limit: $258 \quad 0.2 \mathrm{NH}_{3}-\mathrm{N} \mathrm{mg} / \mathrm{L}, 99 \%$ ile limit: $0.5 \mathrm{NH}_{3}-\mathrm{N} \mathrm{mg/L)} \mathrm{are} \mathrm{applied} \mathrm{in} \mathrm{Step} \mathrm{III.}$

$$
\operatorname{Min}(\text { Costoperation })=\operatorname{Min}\left(C_{\text {pump }}+C_{\text {aeration }}+C_{\text {sludge }}\right)
$$

where $C_{\text {pump }}(\$)$ is the pumping cost, $C_{\text {aeration }}(\$)$ is the aeration cost, $C_{\text {sludge }}(\$)$ is the energy cost for sludge dewatering, $A M M 90 \%$ ile $\left(\mathrm{NH}_{3}-\mathrm{N} \mathrm{mg} / \mathrm{L}\right)$ and $A M M 99 \%$ ile $\left(\mathrm{NH}_{3}-\mathrm{N}\right.$ $\mathrm{mg} / \mathrm{L}$ ) are the $90 \%$ ile and $99 \%$ ile total ammonia concentrations in reach 11 (after all wastewater discharges). The expenditures incurred in pumping, aeration and sludge dewatering constitute the key elements of operational cost, and their detailed formulations are provided in Section S2.

\section{Results}

\subsection{Multi-Objective Optimization of Operational Strategy}

The settings of seven operational variables (highlighted in red in Figure S1) are optimized within reasonable ranges (see Table S3) to minimize the three objectives described in Equations (2) to (4). Other operational handles, i.e. overflow thresholds

273 of tanks 2, 4 and 6, are not considered in the optimization as their value changes are found to have limited impacts on the objectives by a One-At-a-Time (OAT) sensitivity 
analysis $^{49}$ (See details in Section S5). NSGA-II is employed for the optimization and widely accepted settings are used, i.e. population size of 100 , generation number of 30 , crossover index of 20 and mutation index of 20 . Five random runs (i.e. 15,000 yearly simulation runs in total; each run takes about 10 minutes) were conducted which generated 213 Pareto optimal solutions. Though this is computationally demanding, it is feasible as the optimisation is run offline prior to the implementation of online RTC as explained in Section 2.

The Pareto optimal solutions are presented in red circles against the three objectives in Figure $2 \mathrm{a}$ and separately in three pairs in Figures $2 \mathrm{~b}-\mathrm{d}$ (detection limit of total ammonia by current measurement methodologies is no larger than $\left.0.02 \mathrm{mg} / \mathrm{L}^{50,51}\right)$. Each of the Pareto solutions corresponds to an operational solution (i.e. seven diverse set of operational solutions are available to satisfy the good status requirements, though trade-offs exist between the three objectives, i.e. the benefits in one objective cannot be delivered without compromising the system performance in other objectives. For example, a trade-off is observed between the $90 \%$ ile and $99 \%$ ile total ammonia concentrations (Figure 2b), which is due to conflicts between WWTP effluent discharges and overflow spills. A balance can be struck by selecting a solution with preferential $90 \%$ ile and $99 \%$ ile concentration results, which corresponds to distinctive settings of overflow threshold at Tank 7 (controlling Combining Sewer Overflows (CSOs)) and overflow threshold, emptying threshold and emptying rate of the storm tank (affecting intermittent spills in the WWTP). Nevertheless, significant economic and environmental improvements are achieved by the optimal operational solutions and 139 of them dominate the baseline scenario (cost 1.29 Million \$/year) in all the three objectives. Among the good performing solutions, cost can be reduced by 
about $8 \%$ without compromising the environmental outcomes greatly (e.g. the $90 \%$ ile and $99 \%$ ile of the lowest cost solution are $0.18 \mathrm{NH}_{3}-\mathrm{N} \mathrm{mg} / \mathrm{L}$ and $0.57 \mathrm{NH}_{3}-\mathrm{N} \mathrm{mg} / \mathrm{L}$ respectively, which are $53 \%$ and $32 \%$ lower than the baseline scenario).
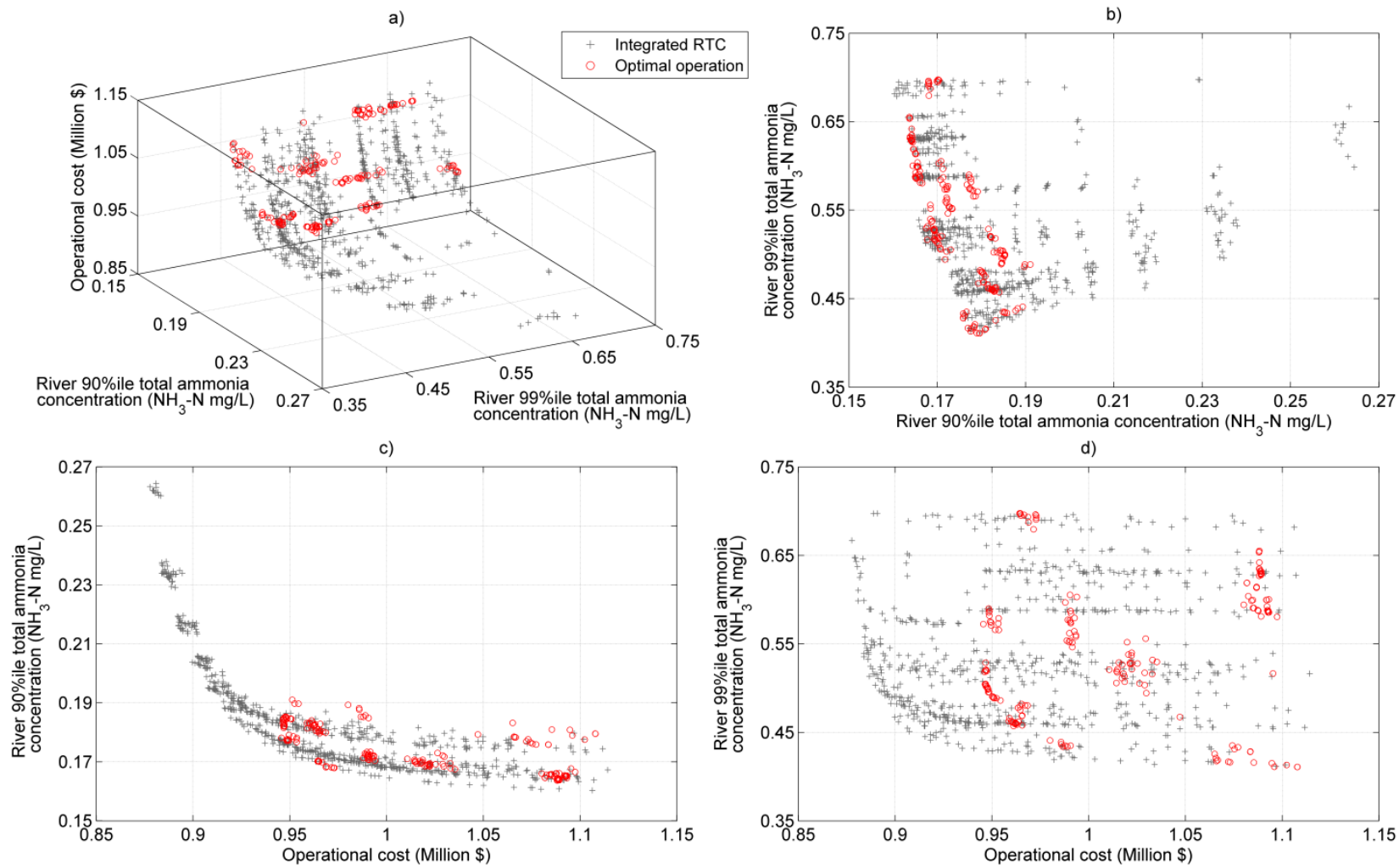

Figure 2 Optimal operational strategies (in red circles) and integrated RTC strategies (in grey crosses) satisfying WFD good status requirements on total ammonia concentration, which are projected against three objectives of operational cost and river 90\%ile and 99\%ile total ammonia concentrations in a) and separately in three pairs in b) to d)

\subsection{Multi-Objective Optimization of Integrated RTC Strategy}

Air flow rate is selected as the only controlled variable (i.e. actuator) because it is one of the most influencing factors for operational cost and water quality as revealed in the OAT sensitivity analysis (see details in Section S5) and is suitable for frequent operational change compared to sludge pumping rates and threshold limit controlling WWTP inflow rate. Three variables are monitored for the aeration control, which are upstream river flow rate (at river reach 2, before all wastewater discharge points), wastewater inflow rate to the WWTP and wastewater temperature (location of 
sampling points illustrated in Figure S1). The three variables are chosen to represent

317 the river assimilation capacity, wastewater load to be treated and critical environmental factor influencing wastewater treatment efficiency, respectively. Flow rates rather than ammonia concentration are monitored as the sensor is more robust to fouling/clogging, less costly and easier to install and maintain ${ }^{52}$, and there is usually a strong correlation between influent flow and ammonia load ${ }^{53}$. As such, the control algorithm is formulated in "If-Then" rules as below. It is applied at each time step (15 minutes) to determine the aeration value based on real-time values of the three monitored variables.

"If river flow rate $>=X_{1}$, wastewater inflow rate $>=X_{3}$ and temperature $>=X_{3}$, Then aeration rate $=Y$; ....."

The number of rules or scenarios depends on how the value of each monitored variable is classified. To minimize the complexity of the controller algorithm, two classes of 'low' and 'high' are defined for all the three variables which makes eight scenarios in total. The threshold limits can be quantified by optimization techniques, however, they are determined here by trial-and-error method facilitated by model simulation due to the nature of the monitored variables. Values of $41,250 \mathrm{~m}^{3} / \mathrm{d}$ (1.5DWF, maximum WWTP inflow rate under dry weather), $15^{\circ} \mathrm{C}$ (defined winter temperature) and $300,000 \mathrm{~m}^{3} / \mathrm{d}$ (10DWF, median annual river flow rate) are used to classify dry/wet weather, winter/non-winter time and low/high river flow. The eight aeration rate values for the control action are simplified into two tiers $Y_{1}$ and $Y_{2}\left(Y_{1}<\right.$ $\mathrm{Y}_{2}$ ), as justified by preliminary optimisation results using more aeration tiers (see details in Section S6). Again by trial-and-error, $Y_{1}$ or $Y_{2}$ is assigned to each of the eight scenarios based on model simulation and validated by an OAT sensitivity analysis (see details in Section S5). For example, in summer time and with no or light rainfall and high river flow rate, the lower aeration rate $Y_{1}$ would be enough as the wastewater 
342 treatment efficiency is relatively high due to the higher temperature and lower loading

343 to the treatment process and higher assimilation capacity of the receiving water. The 'If-Then' rules are summarized and reformatted in Table S4.

The developed control algorithm is applied to all optimal operational solutions derived in Section 4.1, and the values of the two aeration tiers are optimized for each solution against the three pre-defined objectives (i.e. all operational variable values are unchanged except the air flow rate). LHS is used here as there are only two optimisation variables, however, NSGA-II as presented earlier can be employed when more variables have to be considered. 774 Pareto optimal RTC solutions are obtained and are shown in grey dots in Figure 2. Though they do not outperform the optimal operational solutions in all three objectives, more diverse system performance (i.e. wider objective value ranges) is achieved especially the significant cost reduction. The lowest RTC solution can be $15 \%(\$ 155,000)$ cheaper than the baseline scenario, which almost doubles the best achievable benefit by optimization of system operation, and provides improved river water quality (90\%ile and $99 \%$ ile ammonia concentrations are $32 \%$ and $20 \%$ lower than baseline). concentration value. The $99 \%$ ile concentration value is much less correlated with cost (Figure $2 \mathrm{~d}$ ), as it is greatly affected by the higher aeration tier value which has lower cost consequences due to the less frequent occurrence of critical conditions. Informed by the trade-off relationships between the three objectives, cost-effective solutions can be identified that have low cost and are environmentally protective in mitigating the 
impacts of intensive rainfalls (i.e. producing low 99\%ile values) without causing much

367

increase in the $90 \%$ ile concentration level. A screening procedure ${ }^{12}$ can be applied to select the best performing solution(s) suited to local needs and priorities, which can involve defining threshold limits of objective values, restricting values of certain operational handles, and examining the uncertainty of solution performance.

\subsection{Compliance Analysis with Tightening Environmental Standards}

To evaluate the change in the compliance cost under more stringent regulatory requirements, tighter 90\%ile and 99\%ile limit constraints are imposed (at $20 \%$ incremental step) from 'good status' requirements to 'high status' ones. Compliant operational/RTC solutions entailing lower costs than the baseline scenario are identified for analysis, which are obtained by screening the optimal results produced in Sections 4.1 and 4.2 without the need for running $10(5 \times 2)$ optimizations.

The performance of compliant operational/control solutions under different regulatory settings is shown in Figure 3. Each boxplot presents the distribution (minimum, 25\%ile, median, 75\%ile and maximum) in the performance of the compliant operational or RTC solutions (in black or grey box) under certain standard limits. It can be seen from Figure 3a that the (lower) boundaries and distributions of cost are subject to minor changes before the environmental standards are tightened by $80 \%$ along the ranges. Despite the decreasing economic advantage of applying integrated RTC under stricter standards, a $12 \%$ cost saving (than baseline) is still achievable under the 'high status' requirements. The benefits are gained by exploring the dynamic dilution capacity of the environment and utilizing the headroom available for the standard compliance, especially for the $90 \%$ ile limits as shown in Figure $3 \mathrm{~b}$. 
a)

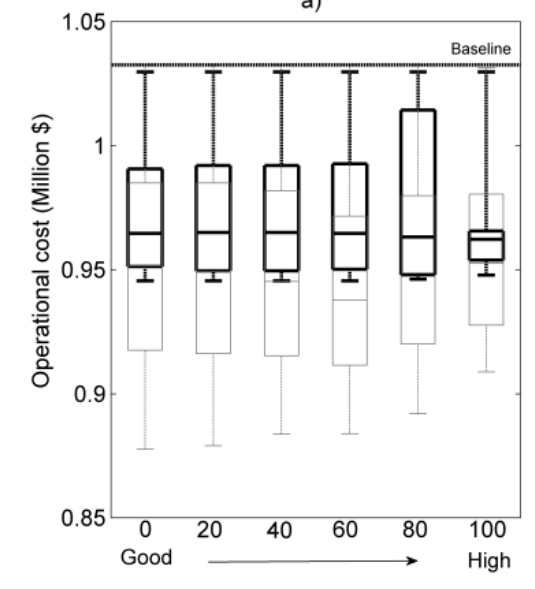

b)

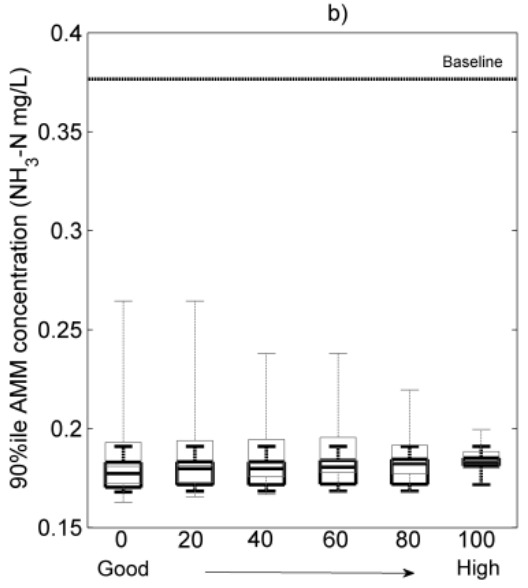

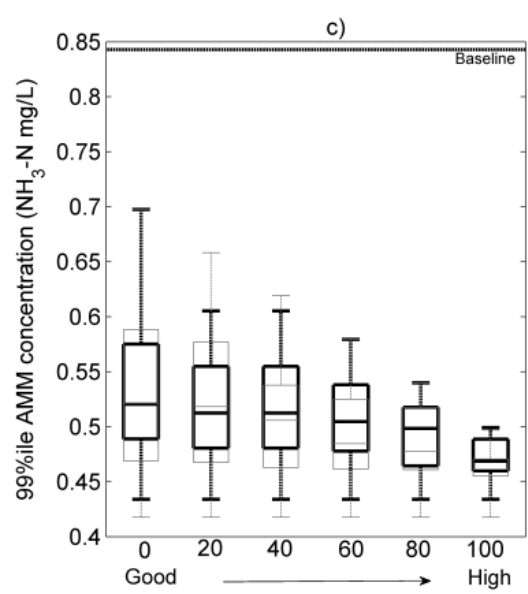

389

Figure 3 Boundaries and distributions of the performance of optimal operational and control solutions (a) Operational cost, b) 90\%ile total ammonia concentration, c) 99\%ile total ammonia concentration) under tightening environmental standards presented in black and grey boxes

The cost-effectiveness of the integrated RTC strategy is further illustrated by seven typical solutions shown in Figure 4. Solutions with colours nearer to the bottom of the colour bar entail lower costs and those located closer to the bottom left corner of the figure produce better environmental water quality. The baseline scenario (i.e. 'Baseline (OO)') violates the $90 \%$ ile and $99 \%$ ile limits for 'good status' requirements. The traditional strategy of intensifying aeration rate (to the highest reasonable value) (i.e. 'Baseline $(\mathrm{OO})-\max \mathrm{O}_{2}$ ') requires $16 \%$ more cost but is still insufficient to comply with the standard limits. By changing the operational settings of the system to the strategy 'GoodSol (OO)', the good status standard limits can be met and the cost is reduced by $8 \%$ than the baseline scenario. The application of real-time aeration control (i.e. 'GoodSol (RTC)') can reduce the operational cost further by $6 \%$. Similar results are produced when the environmental standards become stricter, i.e. optimization of system operation/control is much more cost-effective than the traditional compliance strategy and cheaper RTC solutions can always be found in reaching any given level 
of environmental targets. This can be suggested by the other three solutions in this figure, i.e. 'GoodSol (OO) - max O2', 'HighSol (OO)' and 'HighSol (RTC)'.

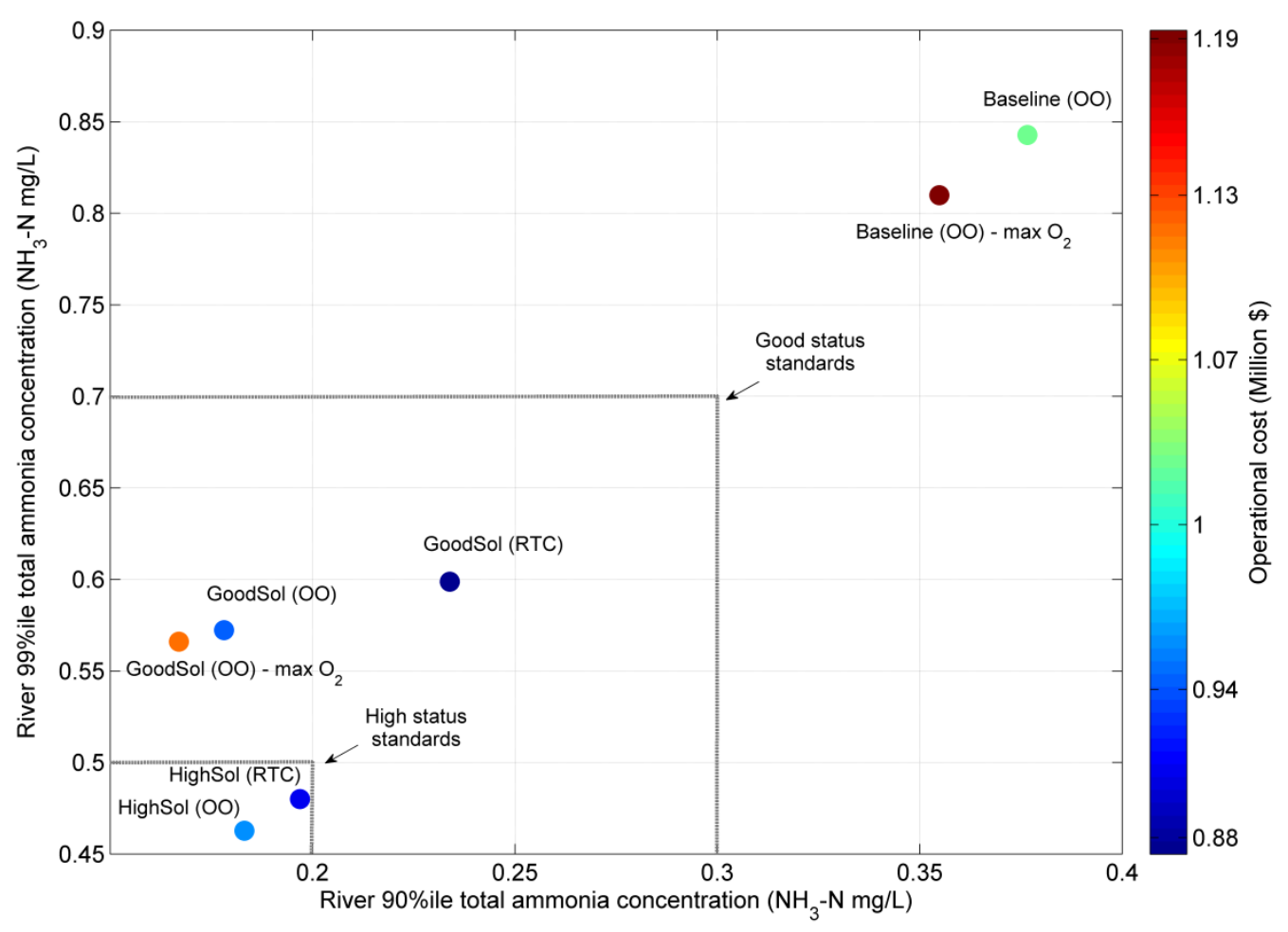

Figure 4 Illustration by seven typical solutions of the impacts of aeration enhancement, operation optimization and integrated RTC in improving environmental and economic performance (OO: optimal operation; RTC: integrated RTC; $\max \mathrm{O}_{2}$ : maximum aeration rate)

To test the uncertainty of system performance, uncertainty analysis is conducted against rainfall inputs, which is a key source of uncertainty and of common interests driven by the threat of climate change. 100 one-year historical rainfall time series from different areas in the UK are applied, which vary in pattern and intensity with half of them having larger total depth (maximally $50 \%$ more) than the rainfall data used earlier. Results are illustrated in Section S7 by using two operational/control solutions, i.e. GoodSol (OO) and GoodRTC (RTC) in Figure 4. It is shown that the $90 \%$ ile total ammonia concentration (mainly influenced by WWTP effluent discharge) is strongly positively correlated with total rainfall depth and the investigated RTC solution can withstand $30 \%$ more intensive rainfall without violating the standard limit. This 
suggests a high robustness of the strategy to precipitation changes, as a $10 \%$ rainfall increase (in total depth) until 2050 is used by regulators in the UK for the preparation of climate change ${ }^{8}$. In comparison, the correlation between the $99 \%$ ile total ammonia concentration and rainfall depth is weaker (the same is true for the static operational solution GoodSol (OO)). This implies that sewer overflows are also affected by rainfall patterns, and control measures in the sewer system should be jointly used if high confidence of compliance of $99 \%$ ile standard limit is sought.

\subsection{Environmental Analysis beyond Regulatory Requirements}

The compliant solutions identified in Section 4.3 are assessed against the four risk and resilience indicators defined in Section 2 to provide further insights into the environmental impacts of the integrated RTC strategy. Results are presented in Figure
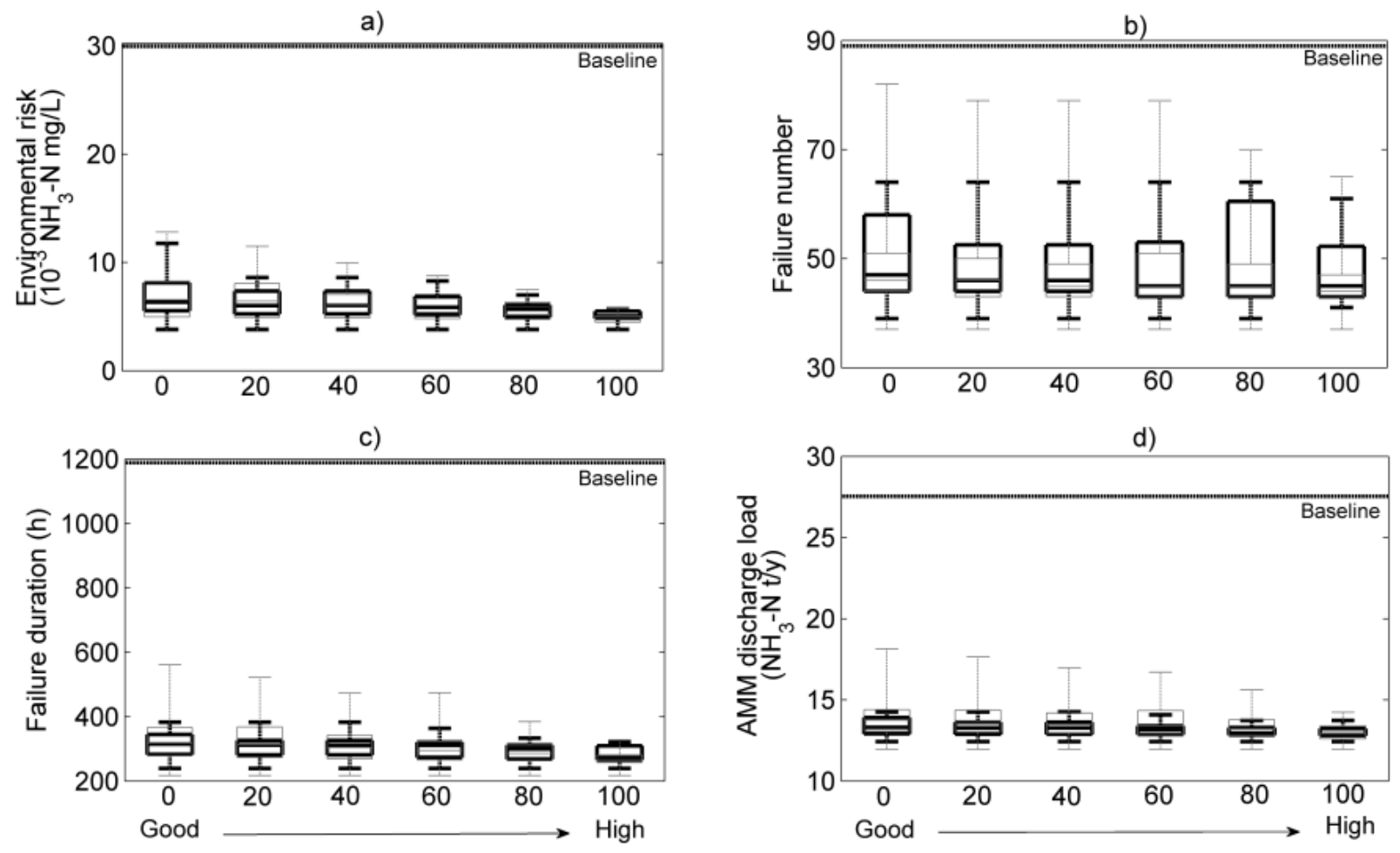

Environmental targets as a percentage between good and high status requirements (\%) RTC solutions (in black and grey boxes respectively) in environmental risk (a), failure 
number (b), failure duration (c) and total ammonia discharge load (d) when the (90\%ile and 99\%ile) environmental targets are tightened from good status to high status standards

442 The combined use of the $90 \%$ ile and $99 \%$ ile concentration limits is effective in enforcing better environmental quality. This can be reflected by the superiority of the optimal operational/RTC solutions to the baseline scenario at any given level of regulatory requirements, and the narrowing performance ranges of the compliant operational/RTC solutions when the $90 \%$ ile and $99 \%$ ile standard limits are tightened. Nevertheless, a detailed risk analysis would still offer value as the upper performance boundaries of the four risk and resilience indicators do not decrease linearly with the stricter standard limits, hence a solution producing lower $90 \%$ ile/99\%ile values does not necessarily yield lower environmental impacts.

\section{Discussion}

\subsection{Comparison of Integrated RTC with Current Flexible Operational} Practices

To further understand the value of timely responsive operation, the integrated RTC strategy is compared with the current flexible practices simulated here as control strategies with longer time steps (i.e. in days, months and seasons). To achieve this, the daily, monthly and seasonally (winter or non-winter) average values of upstream river flow rate, wastewater inflow rate and temperature are calculated first. The 'IfThen' control rules of two example RTC solutions ('HighSol (RTC)' and 'GoodSol (RTC)' in Figure 4) are then applied to derive the aeration value of each (daily, monthly, seasonally) time step. Dynamic simulation is performed for each operational option to appraise and compare their environmental and economic outcomes. Results are normalized and presented in the spider plots in Figure 6 with the maximum values shown in brackets. 


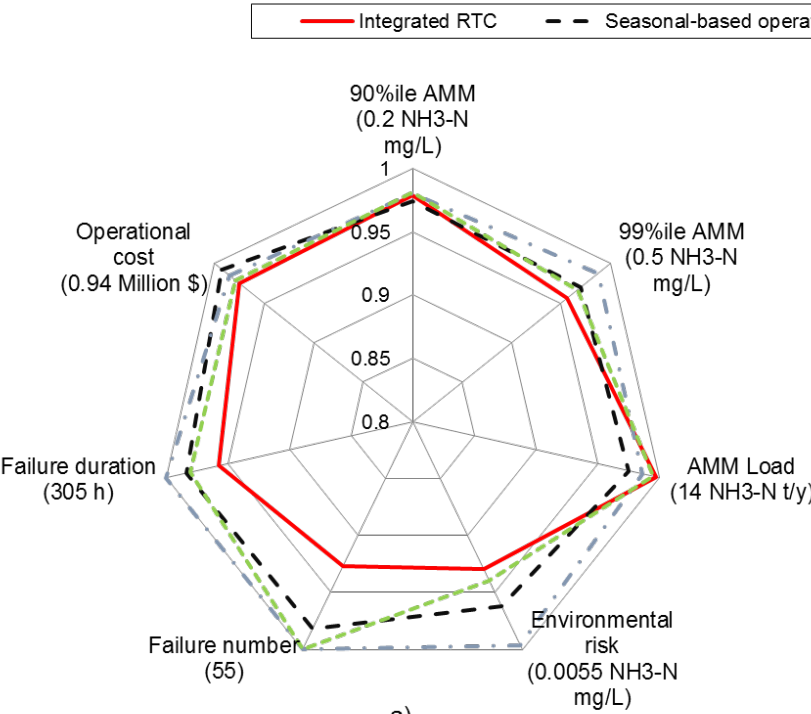

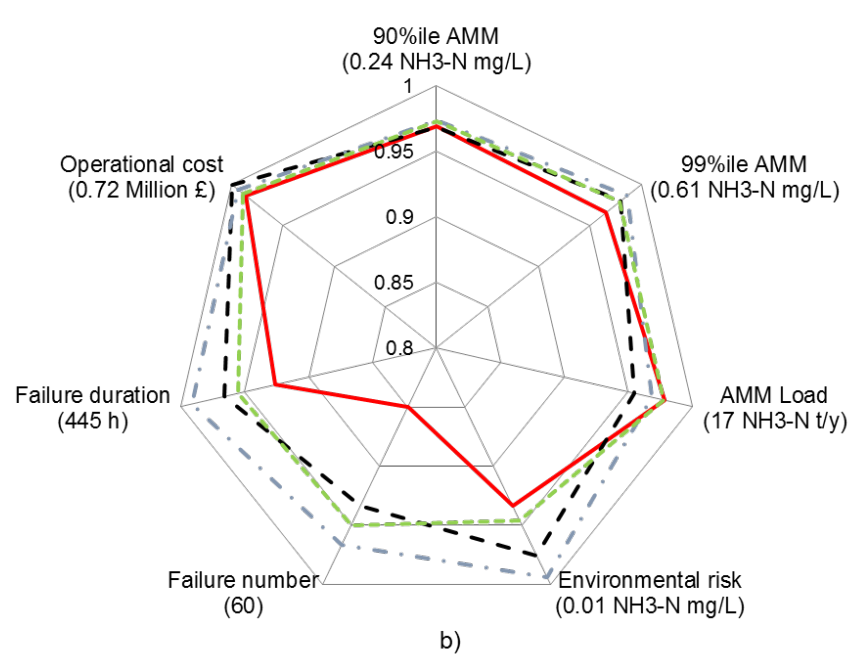

b)

Figure 6 Comparison of the environmental and economic impacts of integrated RTC strategies 'HighSol (RTC) (a) and 'GoodSol (RTC)" (b) (in red lines) with three current flexible practices (i.e. seasonal-based, monthly-based, and daily-based operation) (in black, blue and green lines respectively) (90\%ile AMM: 90\%ile total ammonia concentration, 99\%ile AMM: 99\%ile total ammonia concentration, AMM load: annual discharge load of total ammonia to the river)

As suggested in Figure 6, with a smaller control time step, the operational cost can be slightly reduced. For example, the operational cost savings of 'HighSol can be increased from $9 \%$ to $11 \%$ if adopting (15-minute time step) integrated RTC rather than seasonal operation. This is achieved by more accurate detection of environmental changes (e.g. the ratios between the maximum to minimum river flow rates averaged within seasons, months and days are 3,9 and 10 respectively) and applying less intensive treatment effort under moderate conditions. The exploitation of the dynamic dilution capacity leads to a rise in the total amount of ammonia discharged to the river, however it has minor environmental consequences as ammonia decays and/or is assimilated by aquatic plants quickly and tend not to accumulate in the river under acceptably low concentrations ${ }^{54,55}$.

Compared to the cost benefits, the advantage of integrated RTC is more evident in reducing risk and enhancing resilience of the system, as shown in the smaller values 
of $99 \%$ ile total ammonia concentration, environmental risk, failure number and failure duration than the other three options. However, a smaller control time step does not necessarily results in better environmental outcomes if not implemented in real-time scale. This can be suggested by the worse environmental results of monthly-based operation compared to seasonal operation, and the high failure number by daily based operation.

It should be noted that the results of the seasonal/monthly/daily based operation simulated here should be better than what is best achievable in practice. This is because the average river flow rates used to derive the aeration values are based on the same data set used for the simulation and evaluation, indicating perfect prediction of the environmental changes at each next time step. This is hardly achievable and research has revealed the importance of the accuracy of forecasting in delivering the potential benefits ${ }^{56}$. Moreover, historical data records rather than predictive values are used for seasonal/monthly based operation in practice, which will lead to further decrease in the system performance compared to the simulation results presented here. By contrast, the results of the integrated RTC strategy are more representative of what would happen in reality, as the proposed off-line control strategy does not rely on forecasted values and can be easily implemented in real-life.

\subsection{Benefits, Costs and Policy Implications of Applying Integrated RTC}

As illustrated in Section 4.1, the environmental water quality can be improved with reduced operational cost by optimizing fixed operational settings based on a systemwide view of the complex interactions among process units and the trade-offs between conflicting objectives (i.e. Step I). This helps overcome design limitations and modify 
outdated operational settings. The application of integrated RTC in Section 4.2 could double the cost savings and still attain the same level of environmental water quality. Moreover, it offers long-term benefits under an increasingly onerous regulatory climate and improves system resilience against unexpected disturbances. The proposed framework is a useful tool in developing cost-effective integrated RTC solutions due to: 1) a set of state-of-the-art modelling, computational and visualisation tools, 2) the tiered approach of optimization (of static operation and control), and 3) a comprehensive compliance and risk analysis. Though aeration control for the treatment of total ammonia is investigated as an example, the proposed integrated RTC framework can be readily applied to other control variables (e.g. WWTP inflow), pollutants or treatment configurations. Local operational strategies for energy saving such as decreasing activated sludge concentration in summer (seasonal operation, not suitable for RTC) can be represented in the simulation and optimised in Step I, laying a stronger basis for RTC application and optimisation in Step II. However, as the framework is based on off-line model-based predictive control, the principles for selecting actuators and placing sensors might be different if other controller type is chosen; surrogate or simplified system model and efficient optimization algorithm/settings may be necessary to implement online optimization of RTC.

The amount of benefits achievable by integrated RTC will, of course, vary from case to case and is influenced by a number of factors. Besides the form of control strategies, it also depends on how optimized the current system operational scheme is, the

530 relative significance of waste emissions from the UWWS to the local environmental quality, the dynamics of the environmental assimilation capacity, and the number and nature (e.g. decay rate, bioaccumulation effects) of the pollutant to be controlled. Also, 533 the intangible benefits should not be neglected such as enhanced process 
understanding, identification and diagnosis of system operational problems and improved decisions based on data analytics from data collected in the long term. Nevertheless, an upfront investment is necessary to purchase and install RTC scheme, such as for control equipment, (additional) sensors, network cabling and computer software. Recurrent costs will also be incurred such as for sensor maintenance and recalibration, personnel training and power for the added instrumentation. The investments required vary on a case by case basis. For example, a total of $\$ 1,700,000$ (capital cost) and $\$ 400,000$ (operational and management costs) are reported for the RTC scheme of the Quebec urban drainage system ${ }^{32}$. Though this is a different control scheme on a 25 times larger system (in terms of DWF), the reported figures are still valuable for understanding the potential benefits of integrated RTC and imply that a less than one year payback time might be possible for the case study. Over the years, sensors have become increasingly cheaper and deployed in the global water industry. As a result, the amount of data available to operators and managers continues to grow at an unprecedented rate, resulting in the creation of large datasets or big data. It is critical to develop RTC systems to unlock the value of data and deliver significant efficiencies of existing urban wastewater systems, which could postpone or eliminate the need for large investments in new infrastructure ${ }^{21}$. A robust decision making should be made by detailed estimation of cost and benefits for the specific case with sufficient supporting information and by comparing with other options such as upgrade/reconfiguration of the treatment technology (e.g. applying denitrification).

To gain buy-in from the water sector on the technology, flexible regulation of permitting may be needed. Under the traditional policy, static year-round numeric water quality limits are imposed on WWTP effluent discharges ${ }^{14,57}$, which would be 
559 greatly with the dynamic environmental conditions. Dynamic end-of-pipe permitting, 560 operational-based permitting ${ }^{12}$ or river quality-based permitting ${ }^{15}$ can be investigated

561 as potential regulatory alternatives. Also, conflicts may rise if there are two or more 562 UWWSs discharging to the same waterbody. To address this, strategic catchment563 level planning would be necessary to simulate the likely environmental outcomes given 564 desirable RTC solutions are adopted separately and to coordinate and adjust the 565 control strategies to attain environmental goals without compromising fairness and 566 equity.

\section{Supporting Information}

568 Definition of the case study site; formulation of operational cost; value ranges for 569 operational variables; If-Then control rules for the case study; OAT analysis results; optimisation results with three aeration tiers; and uncertainty analysis results against

571 rainfall input.

\section{Author Information}

\section{Corresponding Authors}

574 * (G.F.) Phone: +44 (0) 01392 723692; Fax: Fax: +44 (0)1392 217965; E-mail:

575 G.Fu@exeter.ac.uk.

576 * (D.B.) Phone: +44 (0) 01392 724064; Fax: Fax: +44 (0)1392 217965; E-mail:

577 D.Butler@exeter.ac.uk.

\section{$578 \quad$ Notes}

579 The authors declare no competing financial interest.

\section{Acknowledgements}




\section{References}

(1) Zimmerman, J. B.; Mihelcic, J. R.; Smith, J. Global stressors on water quality and quantity. Environ. Sci. Technol. 2008, 42, 4247-4254.

(2) Whitehead, P. G.; Wilby, R. L.; Battarbee, R. W.; Kernan, M. A review of the potential impacts of climate change on surface water quality. Hydrol. Sci. Sci. Hydrol. 2009, 54, 101-123.

(3) Loosdrecht, B. M. C. M. Van; Brdjanovic, D. Anticipating the next century of wastewater treatment. Science. 2014, pp. 1452-1453.

(4) Wastewater Management Fact Sheet: Energy Coservation; U.S. Environmental Protection Agency, Office of Federal Agency: Washington, D.C., 2006; [viewed 24 July 2017] https://nepis.epa.gov/Exe/ZyNET.exe/P100IL6T.TXT?ZyActionD=ZyDocument\&Client $=$ EPA\&Index $=2006+$ Thru $+2010 \&$ Docs $=\&$ Query $=\&$ Time $=\&$ EndTime $=\&$ SearchMethod $=$ 1\&, 2006.

(5) Directive 2000/60/EC Establishing a Framework for Community Action in the Field of Water Policy; Official Journal of the European Communities No L 327, 2000; [viewed 24 July 2017] http://ec.europa.eu/health/endocrine_disruptors/docs/wfd_200060ec_directive_en.pdf.

(6) Changing course through the sustainable implementation of the Water Framework Directive; Severn Trent Water Limited, 2013; [viewed 24 July 2017] https://www.severntrent.com/content/dam/stw/ST_Corporate/About_us/Docs/Changin gCourse-WaterFrameworkDirectiveNov2013.pdf, 2013.

(7) Wang, R.; Eckelman, M. J.; Zimmerman, J. B. Consequential environmental and economic life cycle assessment of green and gray stormwater infrastructures for combined sewer systems. Environ. Sci. Technol. 2013, 47, 11189-11198.

(8) Casal-Campos, A.; Fu, G.; Butler, D.; Moore, A. An integrated environmental assessment of green and gray infrastructure strategies for robust decision making. Environ. Sci. Technol. 2015, 49, 8307-8314.

(9) Vezzaro, L.; Grum, M. A generalised dynamic overflow risk assessment (DORA) for real yime control of urban drainage systems. J. Hydrol. 2014, 515, 292-303. 
(10) Fu, G.; Khu, S.; Butler, D. Optimal distribution and control of storage tank to mitigate the impact of new developments on receiving water quality. J. Environ. Eng. 2010, 136, 335-342.

(11) Quintero, C. A. V. Optimization of urban wastewater systems using model based design and control, PdD Dissertation, UNESCO-IHE, Delft, the Netherlands, 2012.

(12) Meng, F.; Fu, G.; Butler, D. Water quality permitting: from end-of-pipe to operational strategies. Water Res. 2016, 101, 114-126.

(13) Nilsson, C.; Renöfält, B. M. Linking flow regime and water quality in rivers: a challenge to adaptive catchment management. Ecol. Soc. 2008, 13, 18.

(14) How to comply with your environmental permit. Additional guidance for water discharge and groundwater (from point source) activity permits (EPR 7.01); Environment Agency (England and Wales) Regulation Guide, 2011; [viewed 24 July 2017] https://www.gov.uk/government/uploads/system/uploads/attachment_data/file/298081 /LIT_7356_4132bc.pdf.

(15) Better regulation: integrated catchment regulation; UKWIR Report No 10/WW/23/6; UK Water Industry Research Limited: London, 2010.

(16) Lamb, J. C.; Hull, D. B. Current status in use of flexible effluent standards. J. Water Pollut. Control Fed. 1985, 57, 993-998.

(17) Reheis, H. F.; Dozier, J. C.; Word, D. M.; Holland, J. R.; Streamflows, L. O. W. Treatment costs savings through monthly variable effluent limits. J. Water Pollut. Control Fed. 1982, 54, 1224-1230.

(18) Poff, N. L.; Allan, J. D.; Bain, M. B.; Karr, J. R.; Karen, L.; Richter, B. D.; Sparks, R. E.; Stromberg, J. C.; Prestegaard, K. L. The natural flow regime: A paradigm for river conservation and restoration. Bioscience 1997, 47, 769-784.

(19) Vanrolleghem, P.; Benedetti, L.; Meirlaen, J. Modelling and real-time control of the integrated urban wastewater system. Env. Model Softw. 2005, 20, 427-442.

(20) Olsson, G. ICA and me--A subjective review. Water Res. 2012, 46, 1585-1624.

(21) Eggimann, S.; Mutzner, L.; Wani, O.; Schneider, M. Y.; Spuhler, D.; Vitry, M. M. De; Beutler, P.; Maurer, M. The potential of knowing more: A review of data-driven urban water management. Environ. Sci. Technol. 2017, 51, 2538-2553.

(22) Schütze, M.; Butler, D.; Beck, B. Modelling, simulation and control of urban wastewater systems; Springer: London, UK, 2002.

(23) Rauch, W.; Harremoës, P. Genetic algorithms in real time control applied to minimize transient pollution from urban wastewater systems. Water Res. 1999, 33, 1265-1277.

(24) Meirlaen, J.; Assel, J. Van; Vanrolleghem, P. A. Real time control of the integrated urban wastewater system using simultaneously simulating surrogate models. Water Sci. Technol. 2002, 45, 109-116. 
(25) Deb, K.; Member, A.; Pratap, A.; Agarwal, S.; Meyarivan, T. A fast and elitist multiobjective genetic algorithm: NSGA-II. IEEE T Evol. Comput. 2002, 6, 182-197.

(26) Fu, G.; Butler, D.; Khu, S.-T. Multiple objective optimal control of integrated urban wastewater systems. Env. Model Softw. 2008, 23, 225-234.

(27) Sweetapple, C.; Fu, G.; Butler, D. Multi-objective optimisation of wastewater treatment plant control to reduce greenhouse gas emissions. Water Res. 2014, 55, 52-62.

(28) McKay, M. D.; Beckman, R. J.; Conover, W. J. A comparison of three methods for selecting values of input variables in the analysis of output from a computer code. Technometrics. 1979, 21, 239-245.

(29) Olsson, G.; Newell, B. Wastewater Treatment Systems: Modelling, Diagnosis and Control; IWA Publishing, London, 1999.

(30) Sweetapple, C.; Fu, G.; Butler, D. Identifying Sensitive Sources and Key Control Handles for the Reduction of Greenhouse Gas Emissions from Wastewater Treatment. Water Res. 2014, 62, 249-259.

(31) Scheer, M.; Heppeler, D.; Krapp, G.; Nusch, S.; Meßmer, A. Real time control of an integrated system - sewer system and wastewater treatment plant. In International Conference on Urban Drainage Modelling; Dresden, Germany, 2004.

(32) Pleau, M.; Colas, H.; Lavallee, P.; Pelletier, G.; Bonin, R. Global optimal real-time control of the Quebec urban drainage system. Env. Model Softw. 2005, 20, 401-413.

(33) Butler, D.; Schütze, M. Integrating simulation models with a view to optimal control of urban wastewater systems. Env. Model Softw. 2005, 20, 415-426.

(34) The River Basin Districts Typology, Standards and Groundwater Threshold Values (Water Framework Directive) (England and Wales) Directions 2010; Standard 2010 No.38; [viewed 24 July 2017] http://gov.wales/docs/legislation/inforcenonsi/environmental/100804direct38.pdf.

(35) Urban Pollution Management Manual; 3rd ed.; Foundation for Water Research, Marlow, UK,: Foundation for Water Research: Marlow, UK, 2012; [viewed 24 July 2017] http://www.fwr.org/UPM3/.

(36) Aquatic life ambient water quality criteria for ammonia - freshwater 2013; U.S. Environmental Protection Agency Regulation EPA-822-R-13-001, 2013; [viewed 24 July 2017] https://www.epa.gov/sites/production/files/2015-08/documents/aquatic-lifeambient-water-quality-criteria-for-ammonia-freshwater-2013.pdf.

(37) European waters - assessment of status and pressures; European Environment Agency: Copenhagen, 2012; [viewed 24 July 2017] http://www.eea.europa.eu/publications/european-waters-assessment-2012.

(38) Dalyander, P. S.; Cerco, C. F. Integration of a fish bioenergetics model into a spatially explicit water quality model : Application to menhaden in Chesapeake Bay. Ecol. Modell. 2010, 221, 1922-1933. 
(39) Butler, D.; Farmani, R.; Fu, G.; Ward, S.; Diao, K. A New Approach to Urban Water Management: Safe and Sure. Procedia Eng. 2014, 89, 347-354.

(40) Guidance for introducing the total pollutant load control system (TPLCS ); Ministry of the Environment (Japan) Guidance, 2011; [viewed 24 July 2017] http://www.env.go.jp/en/water/ecs/pdf/english.pdf.

(41) Standards for the dimensioning and design of stormwater structures in combined sewers; ATV German Standards A128, 1992.

(42) Lessard, P.; Beck, B. Dynamic modelling of the activated sludge process: A case study. Water Res. 1993, 27, 963-978.

(43) SIMBA 6.0: Simulation of wastewater systems. User's Guide; ifak System Company, Magdeburg, Germany, 2009.

(44) Henze, M.; Gujer, W.; Mino, T.; van Loosdrecht, M. C. M. Activated sludge models ASM1, ASM2, ASM2d and ASM3; IWA Publishing: London, UK, 2000.

(45) Lijklema, L.; Aalderink, R. H.; Ruiter, H. de. Procesbeschrijvingen DUFLOW Zuurstofhuishouding in Stromende En Stagnante Water-Systemen. In DUFLOWwater quality process descriptions (in Dutch); Aalderink, R. H.; Blom, G.; Lijklema, L.; Icke, J.; Ruiter, D. H., Eds.; STOWA: Model Description Document, 1996. [viewed 24 July 2017]

http://www.stowa.nl/Upload/publicaties2/mID_4924_cID_3914_73895750_199818_DUFLOW_waterkwaliteit-procesbeschrijvingen.pdf.

(46) Streeter, H. W.; Phelps, B. A study of the pollution and natural purification of the Ohio river III: factors concerned in the phenomena of oxidation and reaeration; Washington, DC, USA, 1925.

(47) Butler, D.; Davies, J. Urban drainage; 3rd ed.; Spon Press: London, UK, 2011.

(48) Storm water management model. User's Manual Version 5; U.S. Environmental Protection Agency, 2010.

(49) Sweetapple, C.; Fu, G.; Butler, D. Identifying Key Sources of Uncertainty in the Modelling of Greenhouse Gas Emissions from Wastewater Treatment. Water Res. 2013, 47, 4652-4665.

(50) Proposed EQS for Water Framework Directive Annex VIII substances: ammonia (unionised); Environment Agency, 2007; [viewed 24 July 2017] https://www.wfduk.org/sites/default/files/Media/ammonia.pdf.

(51) Method 350.1 Determination of ammonia nitrogen by semi-automated colorimetry; U.S. Environmental Protection Agency, 1993; [viewed 24 July 2017] https://www.epa.gov/sites/production/files/2015-06/documents/epa-350.1.pdf.

(52) Thomas, O.; Pouet, M.-F. Wastewater Quality Monitoring: On-Line/On-Site Measurement. In The Handbook of Environmental Chemistry; Springer: Verlag Berlin Heidelberg, 2005; Vol. 5, pp. 245- 272. 
(53) Wett, B.; Ingerle, K. Feedforward aeration control of a Biocos wastewater treatment plant. Water Sci. Technol. 2001, 43, 85-91.

(54) Avnimelech, Y.; Lacher, M.; Raveh, A. Studies on Lake Kinneret (Sea of Galilee) watershed II. Nitrification and self-purification processes in the Jordan Canyon. Water, Air Soil Pollut. 1981, 15, 87-96.

(55) Toxicological profile for ammonia; U.S. Department of Health and Human Services, 2004; [viewed 24 July 2017] https://www.atsdr.cdc.gov/toxprofiles/tp126.pdf.

(56) Ficchì, A.; Raso, L.; Dorchies, D.; Pianosi, F.; Malaterre, P.; Overloop, P. Van. Optimal operation of the multireservoir system in the Seine river basin using deterministic and ensemble forecasts. J. Water Resour. Plan. Manag. 2016, 142, 112.

(57) NPDES permit writers' manual; U.S. Environmental Protection Agency, Office of Wastewater Management, Washington, DC, USA, 2010. 